Document downloaded from:

http://hdl.handle.net/10251/60186

This paper must be cited as:

Payri González, F.; Payri Marín, R.; Bardi, M.; Carreres Talens, M. (2014). Engine combustion network: Influence of the gas properties on the spray penetration and spreading angle. Experimental Thermal and Fluid Science. 53:236-243.

doi:10.1016/j.expthermflusci.2013.12.014.

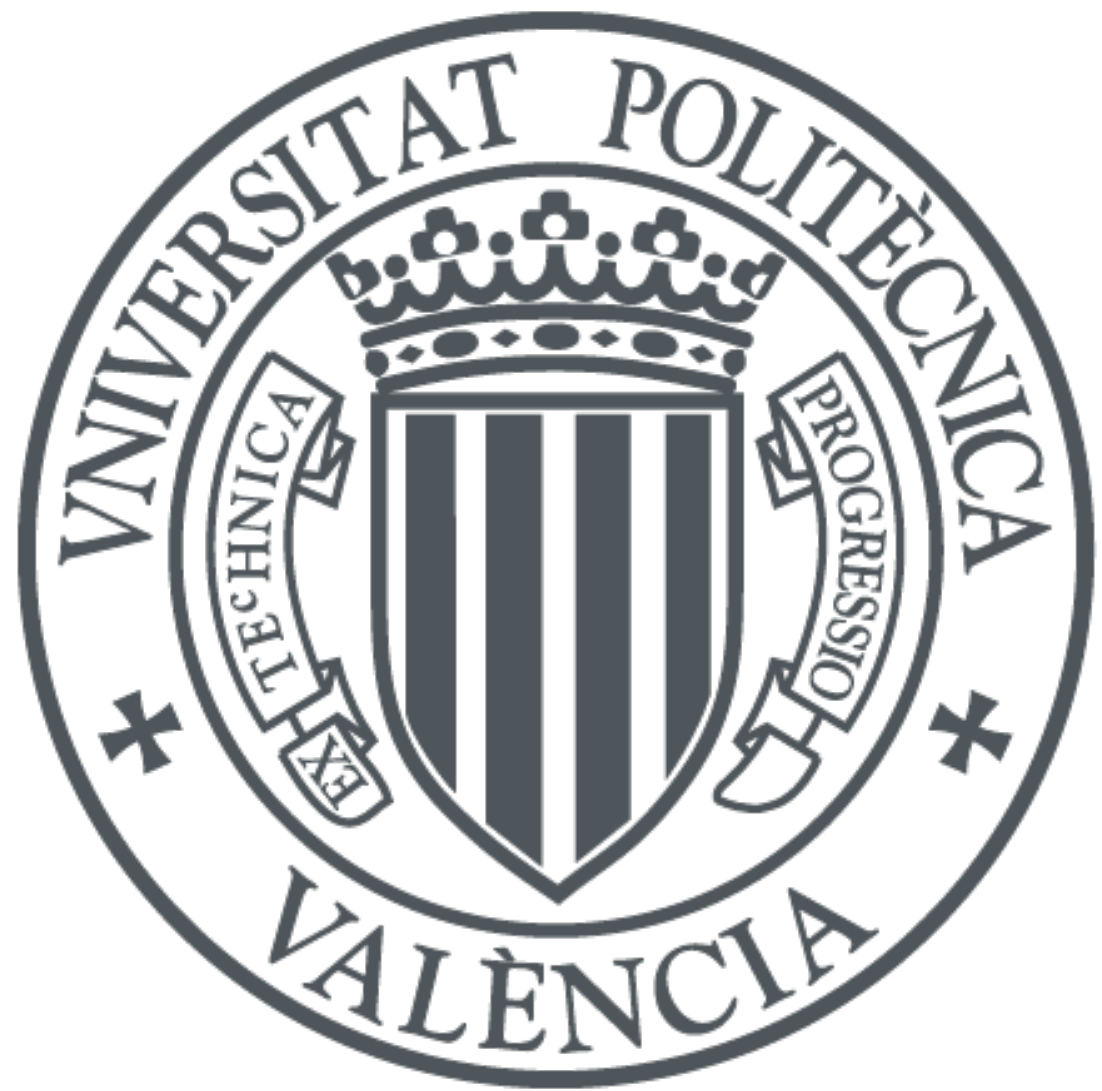

The final publication is available at

http://dx.doi.org/10.1016/j.expthermflusci.2013.12.014

Copyright Elsevier

Additional Information 


\title{
ENGINE COMBUSTION NETWORK: INFLUENCE OF THE GAS PROPERTIES ON THE SPRAY PENETRATION AND SPREADING ANGLE
}

\author{
F. Payri $^{1}$, R. Payri ${ }^{1}$, M. Bardi ${ }^{1}$, M. Carreres ${ }^{1}$
}

fpayri@mot.upv.es,rpayri@mot.upv.es,mbardi@mot.upv.es, marcarta@mot.upv.es

${ }^{1}$ CMT-Motores Térmicos, Universitat Politècnica de València

Camino de Vera s/n, E-46022 Spain.

(*) Corresponding author:

Dr. R. Payri, rpayri@mot.upv.es

CMT-Motores Térmicos, Universitat Politècnica de València

Camino de Vera s/n, València, E-46022 Spain.

Telephone: +34-963879658

FAX: +34-963877659

\section{ABSTRACT}

In this work, three Engine Combustion Network (ECN) single-hole nozzles with the same nominal characteristics have been tested under a wide range of conditions measuring spray penetration and spreading angle. n-dodecane has been injected in nonevaporative conditions at different injection pressures ranging from 50 to $150 \mathrm{MPa}$ and several levels of ambient densities from 7.6 to $22.8 \mathrm{~kg} / \mathrm{m}^{3}$. Nitrogen and Sulphur Hexafluoride $\left(\mathrm{SF}_{6}\right)$ atmospheres have been explored and,in the first case, a temperature sweep from 300 to $550 \mathrm{~K}$ at constant gas density has been executed. Mie scattering has been used as the optical technique by employing a fast camera, whereas image processing has been performed through a home-built Matlab code. 
Differences in spray penetration related to spray orifice diameter, spreading angle and start of injection transient have been found for the three injectors. Significant differenceshave been obtained when changing the ambient gas, whereas ambient temperature hardly affects the spray characteristics up to $400 \mathrm{~K}$. However, a reduction in penetration has been observed beyond this point, mainly due to the sensitivity limitation of the technique as fuel evaporation becomes important. The different behavior observed when injecting in different gases could be explained due to the incomplete momentum transfer between spray droplets and entrained gas, together with the fact that there is an important change in speed of sound for the different gases, which affects the initial stage of the injection.

\section{KEYWORDS}

Diesel injection, spray, spray characteristics, Engine Combustion Network

\section{LIST OF NOTATION}

$c$ : speed of sound

$C_{d}$ : orifice discharge coefficient

$D_{i}$ : nozzle orifice inlet diameter

$D_{0}$ : nozzle orifice outlet diameter

$k$-factor: nozzle orifice conicity factor, defined as $k-$ factor $=100 \cdot \frac{D_{i}-D_{0}}{L}$

$L$ : nozzle orifice length

$P_{a m b}$ : ambient pressure

$P_{\text {rail }}$ : rail pressure

$S$ : spray penetration

PUBLISHED AS: Experimental Thermal and Fluid Science 53 (2014) 236-243

http://dx.doi.org/10.1016/j.expthermflusci.2013.12.014 
$T_{a m b}$ : ambient temperature

$t$ : time from the start of injection

$v_{i}$ : instantaneous spray velocity

\section{GREEK SYMBOLS:}

$\triangle P: P_{\text {rail }}-P_{a m b}$

$\rho_{a m b}$ : Ambient density

$\theta$ : spray spreading angle

\section{SUBSCRIPTS:}

av: average

\section{INTRODUCTION}

For several reasons, both experimental studies and Diesel spray modeling are extraordinarily defiant problems that require non-conventional approaches. The spray in the vicinity of the nozzle tip is highly dense. In addition, the ambient gas-fuel interaction occurs at microscopic scales and high velocities, with droplets of less than $30 \mu \mathrm{m}$ travelling faster than $100 \mathrm{~m} / \mathrm{s}$. Therefore, the application of conventional optical techniques is an arduous task, as it is the case of PIV or phase Doppler measurements. This makes the macroscopic characterization of the spray under cold conditions remain an extensively applied technique in order to comprehend the behavior of the spray, since a relatively basic setup leads to reliable results.

Macroscopic characterization of Diesel isothermal sprays has proved itself to be a valuable tool for spray penetration measurements [1][2][3]. On the other hand, it is extremely challenging to obtain quantitative measurements of spreading angle since PUBLISHED AS: Experimental Thermal and Fluid Science 53 (2014) 236-243 http://dx.doi.org/10.1016/j.expthermflusci.2013.12.014 
different studies related the obtained results to the optical setup or the processing technique utilized [4][5][6]. Then, spreading angle measurements cannot be considered quantitative, although qualitative comparisons are enabled by avoiding changes in the optical setup from measurement to measurement, thus providing extremely useful information related to the spray-air mixing process.

In order to promote international collaboration among experimental and computational researchers within the engine combustion field, the ECN (Engine Combustion Network [7]) was created, addressing the research to reference test conditions and identifying priorities for future research. To this end, Bosch donated five single orifice injectors to the ECN with identical nominal characteristics. Several measurements with these injectors have been carried out in order to compare the results obtained in different facilities [8][9] and to assess the techniques utilized [10][11][12]. The majority of these works consisted on allocating one of the injectors to each test facility and assuming an identical behavior due to the manufacturer specification. However, different measurements of the internal nozzle geometry such as X-ray tomography or microscopic orifice imaging [7] pointed out some differences among the a priori identical injectors. In addition, most tests based their efforts on studying only the ECN reference condition called “Spray A” (150 MPa injection pressure, $22.8 \mathrm{~kg} / \mathrm{m}^{3}$ ambient density, $900 \mathrm{~K}$ ambient temperature and $15 \% \mathrm{O}_{2}$ concentration), which is the forum's first priority.

The present work focuses on the comprehension of the behavior of the different injectors beyond "spray A" conditions. Thus, several tests have been carried out in isothermal conditions with three ECN injectors by using Mie scattering technique in a large range of injection pressures and ambient densities. A high-density gas ( $\mathrm{SF}_{6}-$ sulfur hexafluoride) was used to simulate relevant diesel in-cylinder density conditions 
in order to compare the injectors. Additional tests have been performed using Nitrogen and executing a temperature sweep from 300 to 550K with the aim of checking the effect of spray composition and temperature on the measurements.

The results obtained have been analyzed following two approaches: statistical, extracting an empirical correlation from the experimental results, and theoretical, comparing the experimental results to the prediction ofthe 1-D spray model presented by Pastor et al. [13].

\section{EXPERIMENTAL TOOLS}

\subsection{Injection system}

The injection system implemented for the study consists of commercially available components, namely a high pressure volumetric pump driven by an electric motor and a common-rail with pressure regulator controlled by a PID system. Three common-rail solenoid actuated Bosch injectors with the same nominal characteristics are used in this study. The injectors embody a single axial hole with a nominal outlet diameter of 90 $\mu \mathrm{m}$. Conicity (nominal k-factor $=1.5$ ) and hydro-grinding were incorporated so that cavitation is avoided in the orifice and a discharge coefficient $\mathrm{Cd}=0.86$ is achieved. These injectors are three of the single-hole injectors employed by the ECN group during their research. Their actual internal geometry was previously characterized in depth. The results of this characterization are available on the ECN website [7] and summarized in Table 1.

\subsection{Test chambers and optical setup}

Two different test chambers with optical access have been used to perform the Mie scattering technique. The first one (hereinafter referred to as test rig 1 or TRl) was 
conceived for relatively low pressures (up to $0.8 \mathrm{MPa}$ ) bearing in mind the high density of the $\mathrm{SF}_{6}$. On the other hand, the second test rig (test rig 2 or TR2 from now on) made it possible to analyze the effect of gas temperature on spray penetration. The spray was illuminated by two Xenon-arc light sources and a fast camera (Photron SA5) imaged the light that the fuel droplets scattered. The test rigs and the optical components employed in the experiments are described in detail below.

- $\quad$ Test rig 1 (Fig. 1): designed to visualize the spray at ambient temperature in high density conditions. A typical issue for this kind of facilities is the high pressure required to achieve high density, thus leading to a reduced chamber size and limited optical accessibility. In this case, high density is obtained in the chamber by using $\mathrm{SF}_{6}$ gas since its molecular weight is six times higher than that of the $\mathrm{N}_{2}$, making it possible to reach high density while keeping the pressure to a limit. As a result, densities up to $50 \mathrm{~kg} / \mathrm{m}^{3}$ can be achieved even though mechanical limitations set the maximum pressure allowed in the chamber to 0.8 MPa. The gas is recirculated in a closed loop and fuel droplets are scavenged from the test chamber through the use of a root compressor. Spray penetration and spreading angle comparisons were also carried out in $T R 1$ for $\mathrm{SF}_{6}$ and $\mathrm{N}_{2}$ at a relatively low ambient density $\left(7.6 \mathrm{~kg} / \mathrm{m}^{3}\right)$, the maximum that can be achieved in the latter case. A thorough description of this facility is given in [5]. Fig. 1 shows the test rig layout: each of the two light sources illuminates one side of the spray and the camera collects the scattered light in a perpendicular way.

- $\quad$ Test rig 2 (Fig. 2): designed to visualize the spray in a vessel where real diesel engine high-temperature and high-pressure in-cylinder thermodynamic conditions are achieved. A heating system warms a continuous high pressure gas flow before it enters the test chamber. The power supplied by the heaters is 
controlled by a PID system, thus creating steady thermodynamic conditions in the test chamber. In this case, the light sources are arranged in a different manner: one of them is pointing to the spray from the same side of the camera, whereas the second one is pointing the spray head. With this arrangement, the spray tip illumination is optimized, what reduces sensitivity problems at the spray leading edge, in spite of some evaporation taking place. Even though Pickett et al. [8] state that head on illumination may introduce uncertainties with regard to liquid length measurements, it must be noted that the scope of this study is the effect of gas temperature on spray penetration. Attending to the limit test conditions (ambient pressure up to $15 \mathrm{MPa}$ and ambient temperature up to $1000 \mathrm{~K}$ ), the large test chamber (up to $110 \mathrm{~mm}$ of free field) and the wide optical access (three windows with a $128 \mathrm{~mm}$ diameter), this facility constitutes one of the most advanced tools to study the diesel spray. This facility was fully described in [14].

The imaging system used for each test rig is detailed in Table 2.

\subsection{Image Processing Method}

The first step for image processing is image segmentation. This matter has been approached in several ways in the literature [4][5][15]. In the present work, a simple fixed threshold method has been utilized due to the relatively flat background and the non-saturated images. Therefore, a threshold which corresponds to 3\% of the maximum digital level obtained in the core of the spray is selected for image binarization after the background arithmetical subtraction. This method is extensively used in Mie scattering imaging since it scales the sensitivity to the illumination intensity [14][15]. Althoughcamera non linearity and light orientation at a low number of counts influence segmentation sensitivity, spray penetration in non-evaporative conditions remains a 
valuable measurement due to the abrupt decrease in scattered intensity at the spray tip [4][16][17], allowing to compare results in different setups in an easy manner. On the other hand, the droplet number density decreases smoothly along the radial direction [18][19] and Mie signal is very weak at the spray boundaries. Therefore, the spreading angle measured is strictly related to the optical setup and the segmentation method used [18]. For this reason, the spreading angle results of this study will be presented, but only used for qualitative comparisons between tests carried out in the same test rig, where conditions of both illuminating light intensity and orientation remain unchanged.

Once image binarization is completed, the contour of the spray is processed in order to derive the spray penetration and spreading angle as explained by Naber and Siebers [20]. In the method, as depicted in Fig. 3, the penetration is defined as the median of the distance from the injector tip, of the pixel boundaries contained within an arc of $\theta / 2$. The spray angle $\theta$ is defined by building the isosceles triangle of height $S / 2$ and area $A$, using the following equation:

$$
\tan \left(\frac{\theta}{2}\right)=\frac{A}{(S / 2)^{2}}
$$

Due to the fact that the definition of each parameter depends on the other, their calculation shapes an iterative procedure.

In order to be able to qualitatively compare different test conditions, an average spreading angle $\theta_{\mathrm{av}}$ was calculated. As it has been explained, the algorithm implemented to obtain the spreading angle computes the area $A$ through the use of spray penetration. Thus, in order to take into account the spray shape for cases with different penetration rates and perform trustworthy comparisons, the data used for the average spreading angle $\theta_{\text {av }}$ calculation were chosen with a penetration based criterion, which consists of averaging only the angles obtained for penetrations between 35 and $75 \mathrm{~mm}$. 


\subsection{Test Matrix}

A wide range of conditions have been explored in order to study the spray penetration of the three ECN injectors considering also the influence of the gas composition and temperature on the results. The different conditions tested together with the test rigs that have been used are summarized in Table 3.

\section{RESULTS AND DISCUSSION}

\subsection{Comparison between injectors}

Fig. 4 shows the spray penetration results at different test conditions, corresponding to tests in TR1 with SF6 atmosphere (case 1). Consistent differences between the injectors can be observed,although they are always grouped closely for each test condition: nozzle 677 penetrates slower than the others, whereas 678 is the fastest one and 675 is usually in between. A shorter penetration of the nozzle 677 could be expected due to the fact that it has a considerably smaller outlet diameter (c.f. table 1). Anyway, these trends are not followed in every condition tested and must be carefully assumed.

The spreading angle is another key parameter influencing the spray penetration. The average spreading angle $\theta_{\text {av }}$ enables a global comparison of the case 1 results. Again, as shown in Fig. 5, important differences are found between the three injectors: the largest spreading angles are obtained for nozzle 677 while the lowest ones are found for nozzle 678. These results were expected considering the spray penetration trends commented above. An important result seen in Fig. 5 is that the injection pressure does not influence each injector in the same manner. For instance, for an ambient density of $22.8 \mathrm{~kg} / \mathrm{m}^{3}$, an injection pressure increase leads to a decrease in the nozzle 678 spreading angle, whereas the opposite trend can be observed for nozzle 675 . 
The consistency of the data was assessed by checking the values of shot-to-shot standard deviation (obtained as the average of the shot-to-shot standard deviation at each instant), displayed in Table 4. In the case of the penetration results, the standard deviation is less than $2 \mathrm{~mm}$ for all cases, with an average among injectors of $1.49 \mathrm{~mm}$. This fact suggests a fair accuracy from the tests. However, the order of magnitude of the standard deviation is the same as that of the differences in the penetration measurements for different injectors (Fig. 4), which implies that more analysis is needed. With regard to the spreading angle results, the average standard deviation for the different injectors is $0.39^{\circ}$, which is reasonably lower than the differences found between the injectors (Fig. 5).

The spray velocity has also been studied by calculating the spray penetration time derivative, which is virtually the spray tip velocity at a given instant. The instantaneous spray velocity $v_{i}$ is then calculated as:

$$
v_{i}=\frac{\Delta S}{\Delta t}
$$

where $\Delta S$ and $\Delta t$ are the spray penetration variation and time variation between two successive images, respectively. This instantaneous spray velocity is calculated before the repetition average, so as to reduce shot-to-shot repeatability problems. Fig. 6 shows a comparison of spray tip velocity results for the three nozzles under different test conditions. It can be observed that the differences in tip velocity calculated for the three nozzles (and thus in penetration) are only remarkable at the opening. After the first transient, where the velocity even increases for some conditions, the velocities get very close to each other. Therefore, part of the penetration and spreading angle differences reported in Fig. 4 and Fig. 5 can probably be attributed to the dynamic response of the injector rather than to the flow in steady conditions. 


\subsection{Ambient gas effect}

Further conditions were explored in TR1 to analyze the spray penetration and spreading angle in Nitrogen atmosphere at different injection pressures (case 2). The tests were carried out at an ambient density of $7.6 \mathrm{~kg} / \mathrm{m}^{3}$ since it is the highest density achievable with $\mathrm{N}_{2}$ in this test rig due to mechanical resistance limitations. Results were compared to those in $\mathrm{SF}_{6}$ atmosphere previously analyzed. Fig. 7 shows this comparison for two different injection pressures. A considerable difference in spray penetration between the $\mathrm{N}_{2}$ and the $\mathrm{SF}_{6}$ atmospheres is seen in all cases, as it had already been observed by Payri et al. in [21]. However, variations between the illumination setups and the test rigs used in the tests carried out in [21] did not make it possible to be conclusive about the differences observed. In order to obtain a reliable comparison, in case 2 the illumination setup remained unchanged from $\mathrm{SF}_{6}$ to $\mathrm{N}_{2}$ tests. In additionto the slower penetration in the $\mathrm{N}_{2}$ case, Fig. 7 also shows a clear increase in spreading angle. These differences in both penetration and spreading angle are difficult to explain and are probably related to changes in the ambient gas and fuel droplets interaction at a microscopic scale, resulting in a lower effective momentum transfer between them. Moreover, effects of the compressibility of the ambient gas may become important, since there is a significant difference in the speed of sound of both gases: at $7.6 \mathrm{~kg} / \mathrm{m}^{3}$ and $300 \mathrm{~K}, c_{S F 6}$ takes a value of $135.05 \mathrm{~m} / \mathrm{s}$ whereas $c_{N 2}$ is $354.08 \mathrm{~m} / \mathrm{s}$. Recalling Fig. 6 , it can be observed that the spray tip velocity for $\mathrm{SF}_{6}$ is above the speed of sound of the gas at the beginning of the injection. Roisman et al. [22] demonstrate the importance of the interaction between the spray jet and the shock waves that develop in the ambient gas at the beginning of the injection for large enough injection velocities. According to [22], this interaction explains not only the transient behavior of the spray tip velocity, but also the spray tip velocity increase in some cases, as it was observed and pointed out in Fig. 6, since the 
compressed ambient gas behind the shock wave will expand when the jet cross-section enlarges.

In order to better understand the behavior of the spray, the 1-D spray model proposed by Pastor et al. [13]and completed by Desantes et al. [23] has been employed in the two cases. A comparison between the penetration predicted by the model and the one obtained experimentally has been performed. For both $\mathrm{N}_{2}$ and $\mathrm{SF}_{6}$ cases, the model has been tuned to the experimental data by adjusting the spreading angle value to obtain the best match between experimental data and model predictions. As mentioned before, the spreading angle measured in these experiments has to be considered only as a qualitative evaluation, and therefore it cannot be used as an input of the model. Moreover, the first part of the penetration appears to be roughly predicted by the model, and a time-shift has to be introduced in order to compare the data. The introduction of this time-shift is motivated by different reasons: on one hand, the atomization and mixing process is not clearly understood in the near-field and the complete momentum transfer assumption of the 1D model might not be appropriate; on the other hand, the mass flow rate measurements (used as an input for the 1-D model) are not reliable during the opening phase [24] and contribute to the discrepancies between the experiments and the model predictions; moreover, in the near field, the spray tip velocity is of the same order of magnitude of the atmosphere gas speed of sound and, therefore, spray jet - shock wave interactions are expected [25]. However, after this first transient phase, useful information can be extracted seeking the combination of spreading angle and time-shift that allows the model to give the best match to the experimental penetration. Observing the plots of Fig.8, the variation in penetration caused by an increase of the injection pressure is well predicted by the model without changing any other input parameter. On the other hand, when the ambient gas is 
changed, both the spreading angle and the time shift need to be changed. In particular, for $\mathrm{N}_{2}$ cases, the spreading angle has to be increased and the time shift has to be reduced. This result is in agreement with what was previously discussed, and confirms the differences measured experimentally in spreading angle. Moreover, the different time shift obtained for the two cases indicates that in $\mathrm{SF}_{6}$, the interval in which the model does not fit the experimental data is longer, and this fact can be related to the higher difference that exists between spray tip velocity and sound speed in this case. Additional conditions were tested with $\mathrm{N}_{2}$ in TR2 (case 3) in order to study the effects of the ambient temperature on the injection. Fig. 9 displays the spray penetration results of the temperature swipe, together with a case 1 condition for comparative purposes. No significant differences can be observed for ambient temperatures lower than $400 \mathrm{~K}$. At higher temperatures, the spray penetration slightly decreases, especially when the spray penetration is over $40 \mathrm{~mm}$. The tip of the spray is missed at $550 \mathrm{~K}$ due to the important spray evaporation and the lack of sensitivity of the technique. Fig. 10 shows that the distribution of the light scattered by the spray changes as the temperature increases due to the incipient fuel evaporation and the consequent reduction in the droplet size. In the limit case of $550 \mathrm{~K}$, the evaporation is too important and the algorithm is incapable of detecting the spray jet boundaries. Even when the frame rate is not high, the increase of ambient pressure leads to a shortening in the first period of the spray penetration, where it follows a linear dependence with time (see below). This effect agrees with the observations of Araneo [26] and it is probably related to an improvement in momentum transfer between fuel droplets and ambient gas due to the evaporation taking place even when the ambient temperature is lower than the fuel boiling temperature.

In Fig. 9 (right) the spray penetration velocity is compared for a test in $\mathrm{SF}_{6}$ and three different temperatures (300, 400 and $500 \mathrm{~K}$ ) in $\mathrm{N}_{2}$. Even if the differences in the 
absolute velocities are not easy to see, this figure aims to point out the similarity of the fluctuations measured in spray velocity for the $\mathrm{N}_{2}$ cases, and the different characteristics of the curve obtained for $\mathrm{SF}_{6}$. This different oscillations obtained can be linked, once again, to a different acoustic interaction between the spray and the surrounding gas.

\subsection{Statistical analysis}

The data of the $\mathrm{SF}_{6}$ atmosphere tests were used for a statistical analysis to quantify the effect of each test condition on spray penetration. As it was described by Arrègle et al. in [27], the spray penetration behaves in two different manners during the injection: the first stage is characterized by a linear dependence with time, whereas in a second stage the spray is fully developed and the penetration is proportional to the square root of time. As it has been seen in the previous results, the penetration during the first part of the injection is difficult to predict through a conventional model since some features related to the dynamic behavior of the injector are important at this stage. Thus, all the penetration data lower than an arbitrarily chosen value for each ambient density (40 mm for $7.6 \mathrm{~kg} / \mathrm{m} 3$, $35 \mathrm{~mm}$ for $15.2 \mathrm{~kg} / \mathrm{m} 3$ and $30 \mathrm{~mm}$ for $22.8 \mathrm{~kg} / \mathrm{m} 3$ ) were excluded from the analysis, in order to focus only on the fully developed spray. The equation used by Payri et al. in [21] is chosen for the regression:

$$
S=k \cdot \rho_{a m b}^{a} \cdot P_{r a i l}^{b} \cdot \tan \left(\theta_{a v} / 2\right)^{c} \cdot t^{d} \cdot D_{0}^{0.5}
$$

Where $k, a, b, c$ and $d$ are the parameters to be optimized in the regression. The orifice outlet diameter $D_{0}$ was obtained by microscopic orifice imaging (recall Table 1 ). The results of the regression are included in Table 5. The comparison among experimental and predicted data for the case 1 results is shown in Fig. 11 to ensure the 
robustness of the regression. These results are compared to several correlations in the literature, as shown also in Table 5. On one hand, the results have been compared to the theoretical ones derived from the dimensional analysis and used by several authors such as Wakuri et al. [28], Dent [29], Hiroyasu and Arai [30], Naber and Siebers [20], Payri et al. [31] or Dernotte et al. [32]: all these correlations keep the same exponents for the studied variables. The most significant difference is obtained in the dependence on the spreading angle where the value of the related exponent $c$ varied from 0.09 (from experimental results) to 0.5 (from literature). As stated before, this datum is not surprising, since the measurement of the spreading angle cannot be linked between different experimental setup. On the other hand, the correlation by Payri et al. [21] was used as a further term of comparison: this correlation was obtained through the same approach used in the present work, adjusting the exponents of the power law to obtain the best fit to the experimental data. The ambient density exponent $a$ obtained in the present work differs more from the theoretical value than that obtained in [21].

However, the opposite happens for the rail pressure exponent $b$. These differences could be explained by the fact that, in [21], the exponent related to the spreading angle (depending on ambient density and, in a minor way, on the injection pressure) was forced to take the theoretical value of 0.5 : this fact may affect the calculation of the other coefficients.

\section{CONCLUSIONS}

Spray penetration and spreading angle have been measured in a wide range ofDiesellike conditions for three ECN nozzles having the same nominal characteristics. From the comparison of the results obtained from the three injectors the following conclusions can be laid: 
- Injector 677 shows the slowest penetration, in accordance with the outlet orifice measurement. However, injector 678 presents the fastest penetration even though its diameter is lower than the injector 675 one.

- Injector 678 spreading angle is significantly lower than that of the other injectors. This fact partially justifies the higher penetration measured for this injector. In addition, spreading angle does not scale with the injection pressure in the same way for the three injectors, likely as a consequence of differences in the internal flow.

- The comparison of the spray tip velocity (as a time derivative of the penetration) points out that the biggest differences between injectors take place at the very beginning of the injection, which is probably related to needle dynamics.

Further experiments make it possible to assess the influence of gas properties on spray development:

- The measurements performed in different gases $\left(\mathrm{SF}_{6}\right.$ and $\left.\mathrm{N}_{2}\right)$ with the same optical setup, highlighted significant differences in spray development. Faster penetration and smaller spreading angle were measured in the $\mathrm{SF}_{6}$ atmosphere due to a different fuel droplet and ambient gas interaction, possibly related to the compressibility effects becoming more important in the SF6 atmosphere due to the dissimilarity in speed of sound for the two gases.

- $\quad$ The comparison with the results obtained with a 1-dimensional model confirmed previous hypothesis remarking the different behavior of the fuel spray when injected into different gases. On the other hand, the model confirmed the effect of injection pressure.

- When ambient temperature is modified (keeping constant ambient density), measured penetration remains the same up to $450 \mathrm{~K}$, where only slight 
differences become appreciable. The contour of the spray is missed by the processing algorithm at $550 \mathrm{~K}$ due to the incipient evaporation. However, the direct analysis of the images showed that ambient affects the distribution of the scattered intensity also at relatively low ambient temperature (400 K), when no effects on spray penetration are noticed as a consequence of the reduction of the droplets diameter.

Finally, a statistical analysis was performed in order to generate a regression to the experimental data. Results show good agreement to the experimental data under all the tested conditions and the coefficients obtained are not far from what was expected theoretically through the dimensional analysis nor from what was experimentally obtained by the authors in previous works.

\section{ACKNOWLEDGEMENTS}

This work was sponsored by "Ministerio de Economía y Competitividad" of the Spanish Government in the frame of the Project "Comprensión de la influencia de combustibles no convencionales en el proceso de injección y combustióntipo diesel”, Reference TRA2012-36932. Additionally, the coauthor Michele Bardi was financed bya grant from "Conselleria de educacio, culturaiesport" of the "GeneralitatValenciana" in the frame of the project “CaviDiesel”, Reference GRISOLIA/2010/010. This support is gratefully acknowledged by the authors.

The authors would also like to thank Juan Pablo Viera and José Enrique del Rey for their valuable work in the laboratory during the tests. 


\section{BIBLIOGRAPHY}

[1] J.M. Desantes and R. Payri and J.M. Garcia and F.J. Salvador, A contribution to the understanding of isothermal diesel spray dynamics, Fuel 86 (2007), 1093 1101.

[2] C. Chang, P. Farrell, A Study on the Effects of Fuel Viscosity and Nozzle Geometry on High Injection Pressure Diesel Spray Characteristics, SAE Technical Paper 970353, (1997)

[3] Y. Gao, J. Deng, C. Li, F. Dang, Z. Liao, Z. Wu, L. Li, Experimental study of the spray characteristics of biodiesel based on inedible oil, Biotechnology Advances, 27 (5) (2009), 616-624.

[4] V. Macian, R. Payri, A. García, M. Bardi, Experimental Evaluation of the Best Approach for Diesel Spray Images Segmentation, Exp Techniques 36(6) (2012) 26-34.

[5] J.V. Pastor, J. Arrègle, J.M. García, L.D. Zapata, Segmentation of diesel spray images with log-likelihood ratio test algorithm for non-Gaussian distribution, Appl Optics 46(6) (2007) 888-899.

[6] A.K. Agarwal, V.H. Chaudhury, Spray Characteristics of biodiesel/blends in a high pressure constant volume spray chamber, ExpTherm Fluid Sci 42(2012) 212-218.

[7] http://www.sandia.gov/ecn/ Last accessed November $26^{\text {th }} 2012$.

[8] L. Pickett, C. Genzale, G. Bruneaux, L. Malbec et al., Comparison of diesel spray combustion in different high-temperature, high-pressure facilities, SAE Int. J. Engines 3(2) (2010) 156-181.

[9] M. Bardi, R. Payri, L.-M.Malbec,G.Bruneaux, L.M. Pickett, J.Manin, C. Genzale, and T. Bazyn, Engine Combustion Network: Comparison of spray and PUBLISHED AS: Experimental Thermal and Fluid Science 53 (2014) 236-243 http://dx.doi.org/10.1016/j.expthermflusci.2013.12.014 
combustion characterizationin different combustion vessels, Atomization Sprays, 22 (9), 2012.

[10] L. M. Pickett, C.L. Genzale, J. Manin, L-M. Malbec, L. Hermant, “Measurement Uncertainty of Liquid Penetration in Evaporating Diesel Sprays”, ILASS-Americas (2011), Ventura, California, May 15-18, Paper No. 2011-111.

[11] J. E. Nesbitt, S.E. Johnson, L.M. Pickett, D.L. Siebers, S-Y. Lee, J.D. Naber, Minor Species Production from Lean Premixed Combustion and Their Impact on Autoignition of Diesel Surrogates, Energ Fuel 25(3) (2011) 926-936.

[12] M. Meijer, J. Nesbitt, L. M. Pickett, L-M.Malbec, G.Bruneaux, M.Bardi, R.Payri and T.Bazyn, Engine Combustion Network (ECN): Characterization and comparison of boundary conditions for different combustion vessels, Atomization and Sprays, 22 (9) (2012) 777-806.

[13] J.V. Pastor, J.J.Lopez, J.M. Garcia-Oliver, J.M. Pastor. A 1D model for the description of mixing-controlled inert diesel sprays, Fuel 87 (13-14)(2008) 2871-2885.

[14] R. Payri, J.M. García-Oliver, M. Bardi, J. Manin, Fuel temperature influence on Diesel sprays in inert and reacting conditions, ApplThermEng 35 (2012) 185195.

[15] W. Zeng, M. Xu, M. Zhang, Y. Zhang, D.J. Cleary, Macroscopic characteristics for direct-injection multi-hole sprays using dimensionless analysis, ExpTherm Fluid Sci 40 (2012) 81-92.

[16] D. Siebers, Scaling Liquid-Phase Fuel Penetration in Diesel Sprays Based on Mixing-Limited Vaporization, SAE Technical Paper 1999-01-0528 (1999)

[17] F. Payri, J.V. Pastor, A. Palomares, J.E. Juliá, Optimal feature extraction for segmentation of Diesel spray images, Appl Optics 43(10) (2004) 2102-2111. 
[18] L. Pickett, J. Manin, C. Genzale, D. Siebers et al., Relationship Between Diesel Fuel Spray Vapor Penetration/Dispersion and Local Fuel Mixture Fraction, SAE Int. J. Engines 4(1) (2011) 764-799.

[19] R. Payri, L. Araneo, J. Shakal, V. Soare, Phase doppler measurements: system set-up optimization for characterization of a diesel nozzle, J MechSciTechnol 22(8) (2008) 1620-1632.

[20] J. Naber, D. Siebers, Effects of gas density and vaporization on penetration and dispersion of diesel sprays, SAE Technical Paper 960034 (1996).

[21] R. Payri, F.J. Salvador, J. Gimeno, V. Soare, Determination of Diesel Sprays Characteristics in Real Engine In-Cylinder air Density and Pressure Conditions, J MechSciTechnol 19(11) (2005) 2040-2052.

[22] I.V. Roisman, L. Araneo, C. Tropea, Effect of ambient pressure on penetration of a diesel spray, Int J Multiphas Flow 33(8) (2007) 904-920.

[23] J.M. Desantes, J.V. Pastor, J.M.Garcia-Oliver, J.M. Pastor. A 1D model for the description of mixing-controlled reacting diesel sprays, Combustion and Flame, Volume 156, Issue 1, Pages 234-249, 2009

[24] L.M. Pickett, J. Manin, R. Payri, M. Bardi, J. Gimeno, Transient Rate of Injection Effects on Spray Development, SAE Technical Paper 2013-24-0001, (2013).

[25] J. Kostas, D. Honnery, J. Soria et al., Effect of nozzle transients and compressibility on the penetration of fuel sprays, ApplPhysLett 95 (2009).

[26] L. Araneo, "Prediction of Diesel spray penetration with short injections in low density gas”, Thiesel Conference on Thermo and Fluid Dynamic Processes in Diesel Engines (2004), Valencia, Spain, September 7-10. 
[27] J. Arrègle, J.V. Pastor, S. Ruiz, The Influence of Injection Parameters on Diesel Spray Characteristics, SAE Technical Paper 1999-01-0200 (1999).

[28] Y. Wakuri, M. Fujii, T. Amitani, R. Tsnumeya, Studies of the penetration of a fuel spray in a Diesel Engine, B JSME 3(9) (1960) 123-130.

[29] J. Dent, A Basis for the Comparison of Various Experimental Methods for Studying Spray Penetration, SAE Technical Paper 710571 (1971).

[30] H. Hiroyasu, M. Arai, Structures of Fuel Sprays in Diesel Engines, SAE Technical Paper 900475 (1990).

[31] F. Payri, V. Bermúdez, R. Payri, F.J. Salvador, The influence of cavitation on the internal flow and the spray characteristics in diesel injection nozzles, Fuel 83 (2004) 419-431.

[32] J. Dernotte, C. Hespel, S. Houillé, F. Foucher, C. Mounaïm-Rousselle, Influence of fuel properties on the diesel injection process in nonvaporizing conditions, Atomization Spray 22(6) (2012) 461-492. 


\section{LIST OF TABLES}

\begin{tabular}{ccccc}
\hline Injector & $\mathbf{D}_{\mathbf{i}}[\boldsymbol{\mu m}]$ & $\mathbf{D}_{\mathbf{0}}[\boldsymbol{\mu m}]$ & $\mathbf{L}[\boldsymbol{\mu m}]$ & $\mathbf{k}$-factor $[-]$ \\
\hline Nominal & 105 & 90 & - & 1.5 \\
\hline Uncertainty & 2 & 1 & 5 & 0.1 \\
\hline $\mathbf{2 1 0 6 7 5}(*)$ & 116 & 89.4 & 1030 & 2.7 \\
$\mathbf{2 1 0 6 7 7}(*)$ & 116 & 83.7 & 1026 & 3.2 \\
$\mathbf{2 1 0 6 7 8}(*)$ & 117 & 88.6 & 1044 & 2.8 \\
\hline
\end{tabular}

Table 1: ECN nozzle internal geometry characteristics, obtained via X-ray tomography by Caterpillar Inc. [3] (*) Hereinafter, the injectors will be referred to as 675, 677 and 678 , respectively.

\begin{tabular}{|l|c|c|}
\hline & Test rig 1 & Test rig 2 \\
\hline Light source & Double Xe-arc source & Double Xe-arc source \\
\hline Camera & Photron SA5 & Photron SA5 \\
\hline Lens & Nikkor $50 \mathrm{~mm} \mathrm{f/1.8}$ & Nikkor $50 \mathrm{~mm} \mathrm{f} / 1.8$ \\
\hline Pixel/mm & 7.44 & 11.7 \\
\hline Window size & $20 \times 95 \mathrm{~mm}$ & $20 \mathrm{x} 65 \mathrm{~mm}$ \\
\hline Frame rate & $30 \mathrm{kfps}$ & $25 \mathrm{kfps}$ \\
\hline Shutter time & $15 \mu \mathrm{s}$ & $15 \mu \mathrm{s}$ \\
\hline
\end{tabular}

Table 2: Imaging system details for both test rigs. 


\begin{tabular}{|c|c|c|c|}
\hline & Case 1 & Case 2 & Case 3 \\
\hline Test rig & TR1 & TR1 & TR2 \\
\hline $\mathbf{T}_{\mathbf{a m b}}[\mathbf{K}]$ & 300 & 300 & From 300 to 550 \\
\hline Injector \# & $675-677-678$ & 677 & 677 \\
\hline Gas & $\mathrm{SF}_{6}$ & $\mathrm{~N}_{2}$ & $\mathrm{~N}_{2}$ \\
\hline $\boldsymbol{\rho}_{\mathbf{a m b}}\left[\mathbf{k g} / \mathbf{m}^{3}\right]$ & $7.6-15.2-22.8$ & 7.6 & 22.8 \\
\hline
\end{tabular}

Table 3: Test matrix.

\begin{tabular}{ccc}
\hline Injector & $\begin{array}{c}\text { Penetration standard } \\
\text { deviation }[\mathrm{mm}]\end{array}$ & $\begin{array}{c}\text { Spreading angle } \\
\text { standard deviation }\left[{ }^{\circ}\right]\end{array}$ \\
\hline $\mathbf{6 7 5}$ & 1.57 & 0.44 \\
$\mathbf{6 7 7}$ & 1.52 & 0.35 \\
$\mathbf{6 7 8}$ & 1.39 & 0.38 \\
\hline Average & 1.49 & 0.39 \\
\hline
\end{tabular}

Table 4: Standard deviation for the penetration and spreading angle results. The values have been obtained by averaging the shot-to-shot standard deviations obtained for each instant.

\begin{tabular}{|c|c|c|c|c|c|}
\hline & $\mathbf{a}$ & b & c & d & $\mathbf{R}^{2}$ \\
\hline From $\mathrm{SF}_{6}$ tests & -0.33 & 0.24 & -0.09 & 0.51 & 98.8 \\
\hline From $\mathrm{N}_{2}$ tests & -0.33 & 0.24 & -0.09 & 0.54 & 98.6 \\
\hline $\begin{array}{l}\text { From dimensional analysis } \\
\text { - Several authors } \\
{[20][28][29][30][31][32]}\end{array}$ & -0.25 & 0.25 & -0.5 & 0.5 & - \\
\hline From Payri et al. [21] - SF6 & -0.228 & 0.336 & -0.5 & 0.549 & 94.79 \\
\hline From Payri et al. [21] - N2 & -0.268 & 0.254 & -0.5 & 0.513 & 98.14 \\
\hline
\end{tabular}

Table 5: Results of the $\mathrm{SF}_{6}$ and $\mathrm{N}_{2}$ data correlation and comparison with other authors. 


\section{LIST OF FIGURE CAPTIONS}

Figure 1: Sketch of TR1 together with the optical arrangement.

Figure 2: Sketch of TR2 together with the optical arrangement.

Figure 3: Spray penetration $(S)$ and spreading angle $(\theta)$ definition.

Figure 4: Spray penetration results in $T R l$ with $\mathrm{SF}_{6}$ atmosphere (case 1) at different test conditions. Note that the axes have different time scale.

Figure 5: Spreading angle results in $T R 1$ with $\mathrm{SF}_{6}$ atmosphere (case 1) at different test conditions.

Figure 6: Spray tip velocity evolution under different case 1 test conditions.

Figure 7: Penetration and spreading angle comparison $\mathrm{SF}_{6}$ (case 1) and $\mathrm{N}_{2}$ (case 2) atmospheres at $\rho_{a m b}=7.6 \mathrm{~kg} / \mathrm{m}^{3}$ in TR1.

Figure 8: Comparison between experimental data and model results. The 1-D model is adjusted for $\mathrm{SF}_{6}$ case (left) and $\mathrm{N}_{2}$ (right).

Figure 9: Spray penetration results at different ambient temperatures and composition with $\rho_{a m b}=22.8 \mathrm{~kg} / \mathrm{m} 3, P_{\text {rail }}=150 \mathrm{MPa}$ and injector $677 . T R 1$ for the $\mathrm{SF}_{6}$ condition (case 1) and TR2 for the $\mathrm{N}_{2}$ conditions (case 3). A zoom of the first instants is shown for comparative purposes.

Figure 10: Raw images acquired at different ambient temperatures for $\mathrm{N}_{2}$ conditions at $\rho_{a m b}=22.8 \mathrm{~kg} / \mathrm{m} 3, P_{\text {rail }}=150 \mathrm{MPa}$ and injector 677 in TR2 (case 3).

Figure 11: Spray penetration predicted values versus experimental data (case 1) 


\section{LIST OF FIGURES}

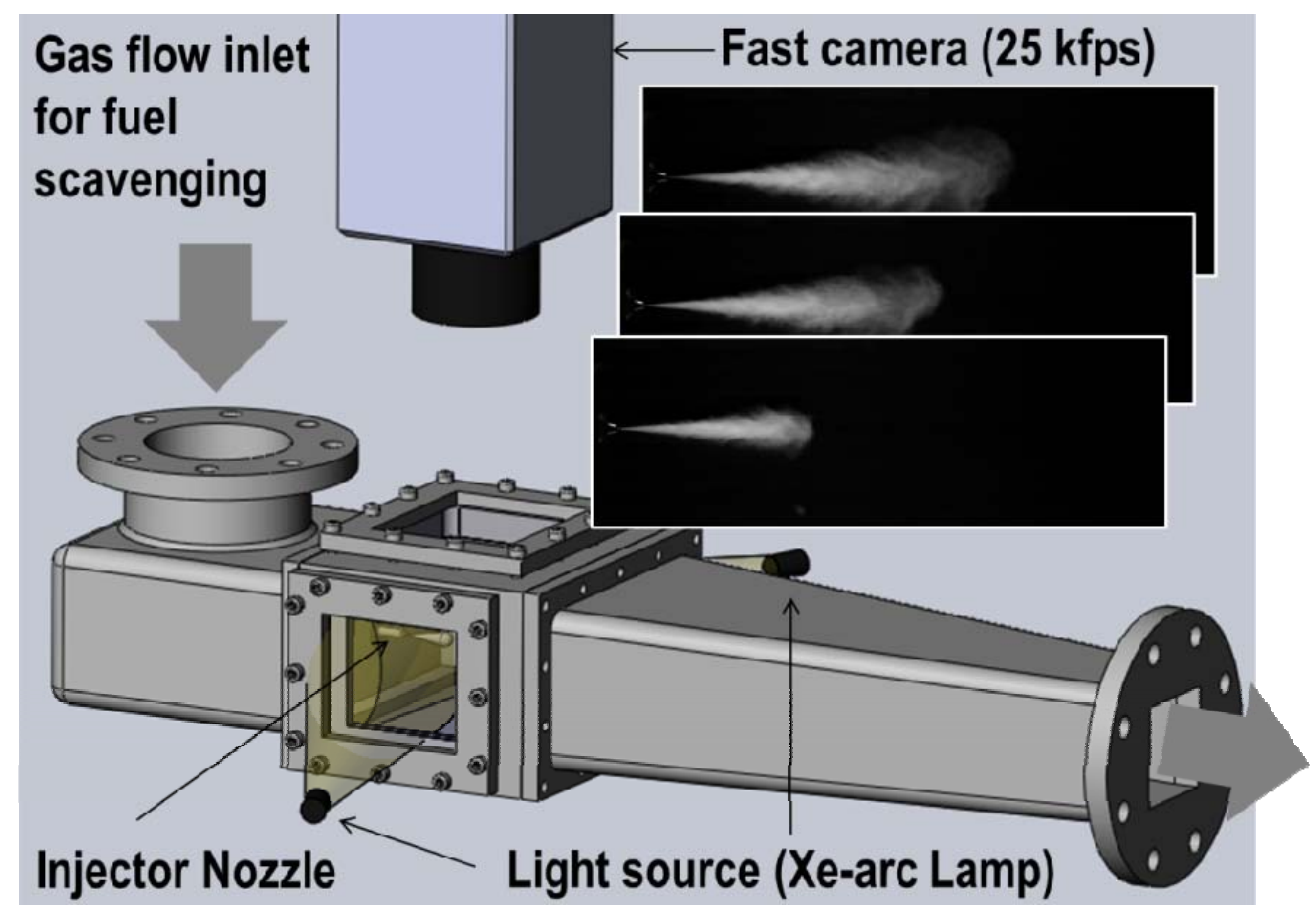

Figure1

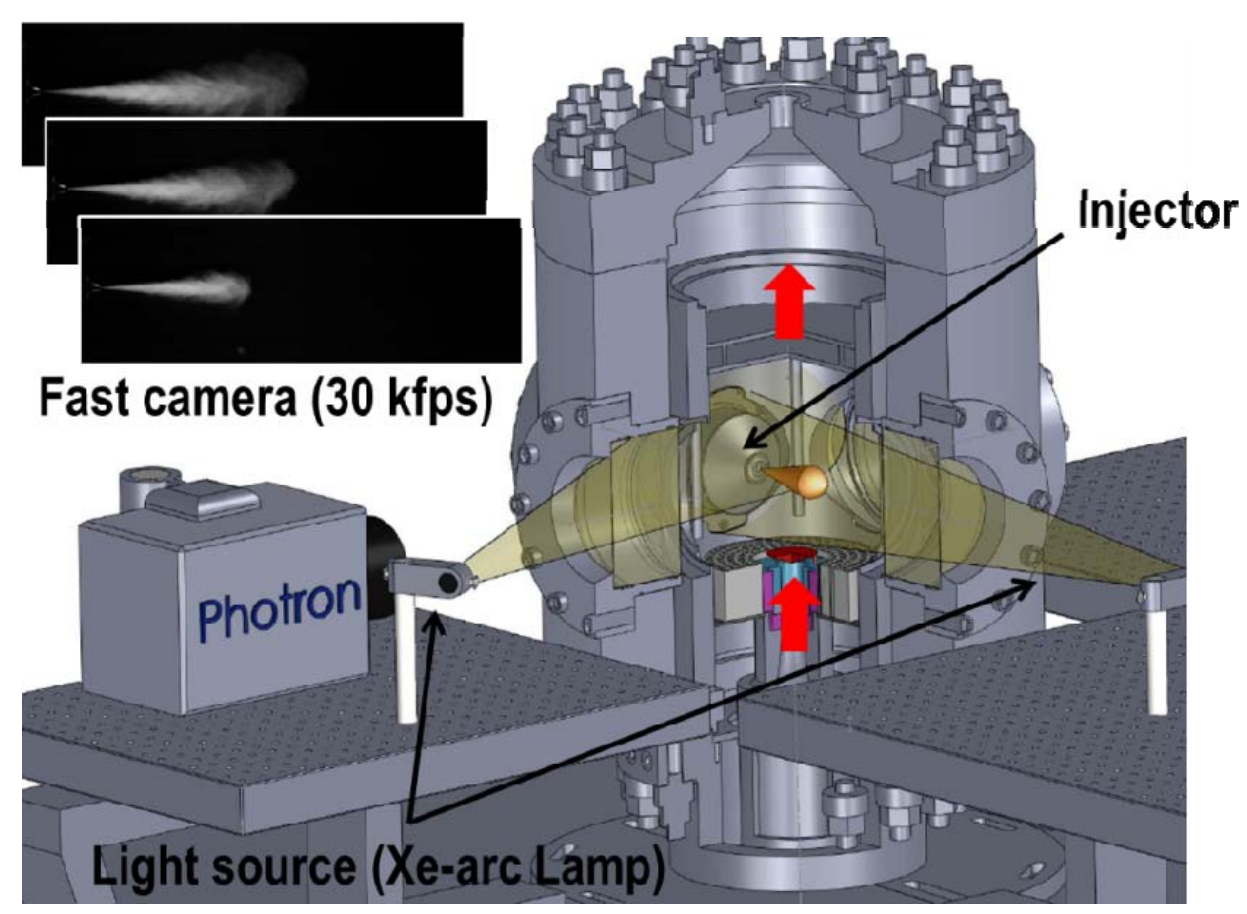

Figure2

PUBLISHED AS: Experimental Thermal and Fluid Science 53 (2014) 236-243 http://dx.doi.org/10.1016/j.expthermflusci.2013.12.014 


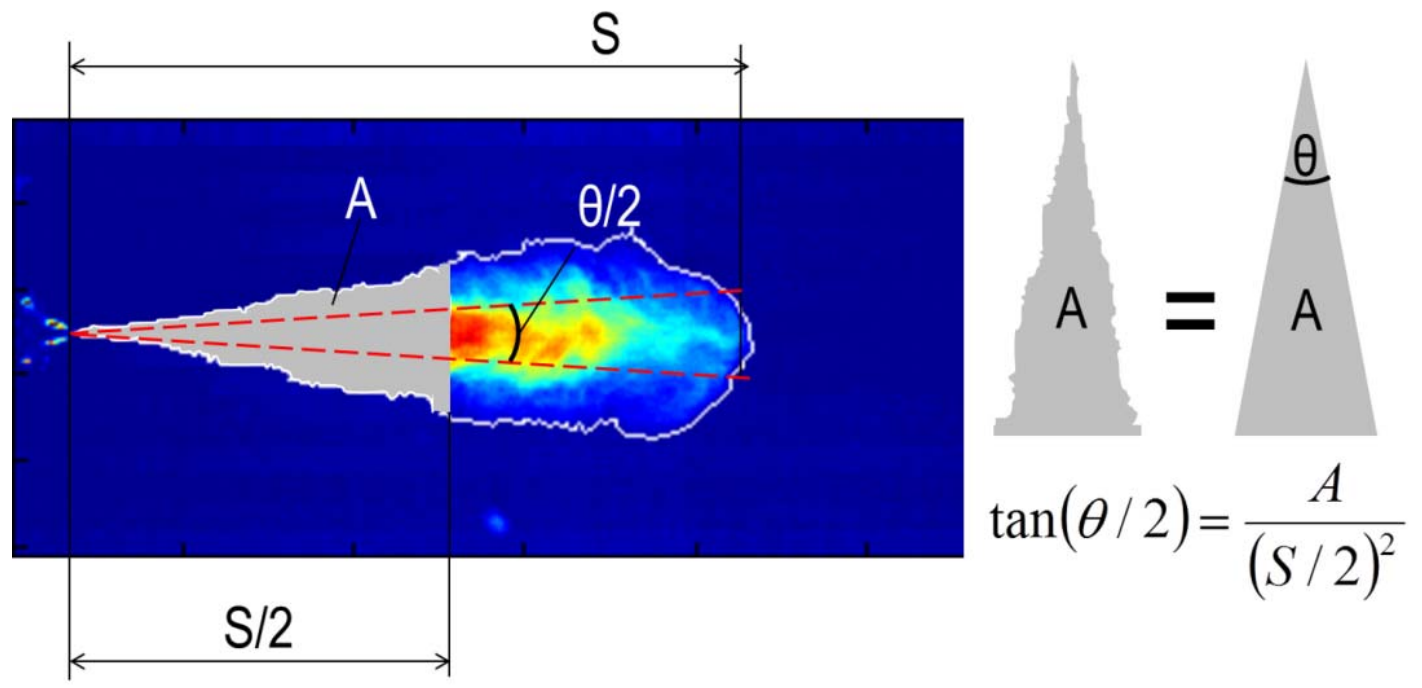

Figure3
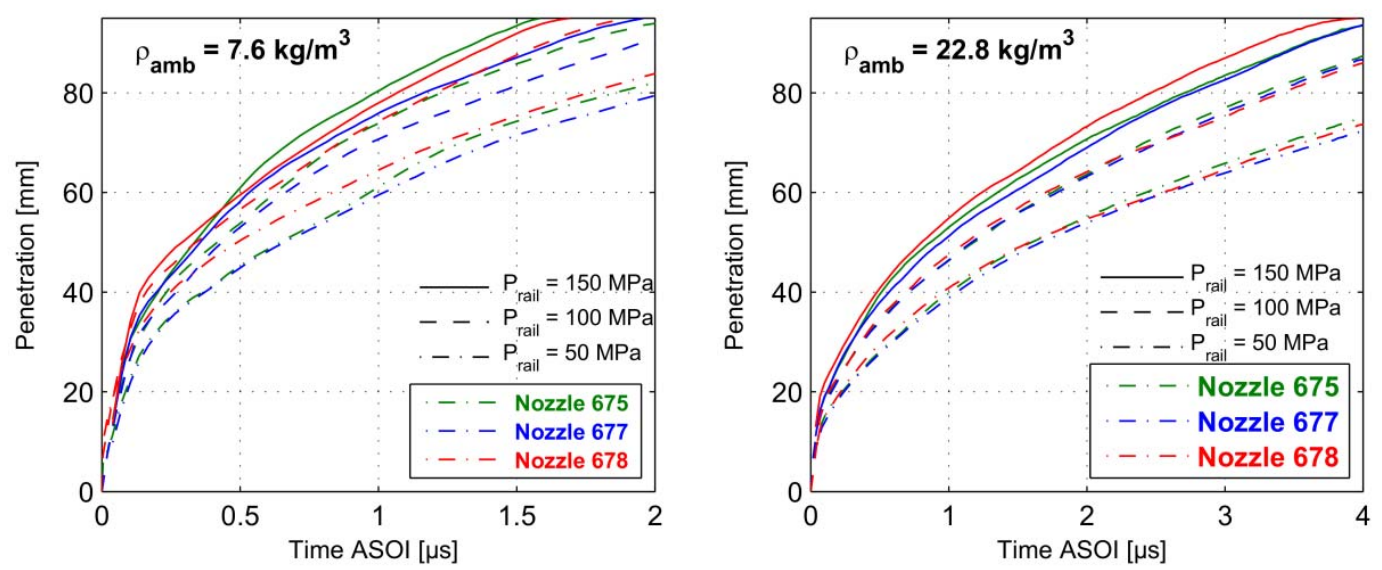

Figure4

PUBLISHED AS: Experimental Thermal and Fluid Science 53 (2014) 236-243 http://dx.doi.org/10.1016/j.expthermflusci.2013.12.014 


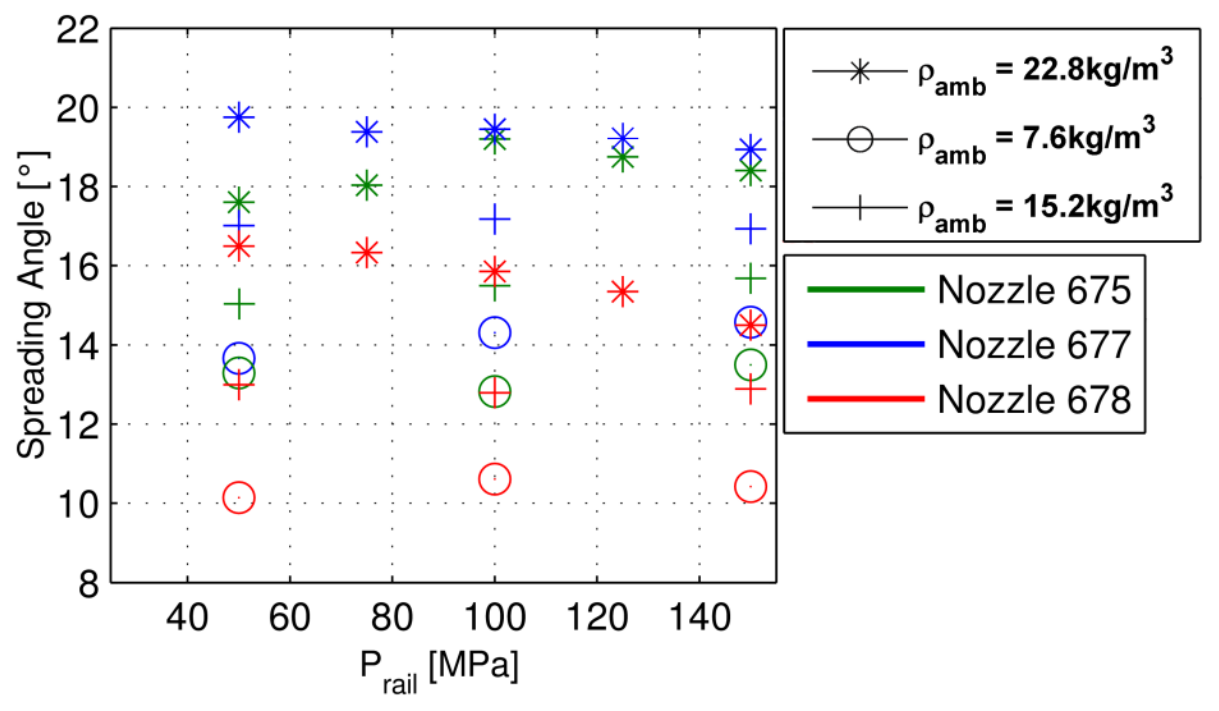

Figure5
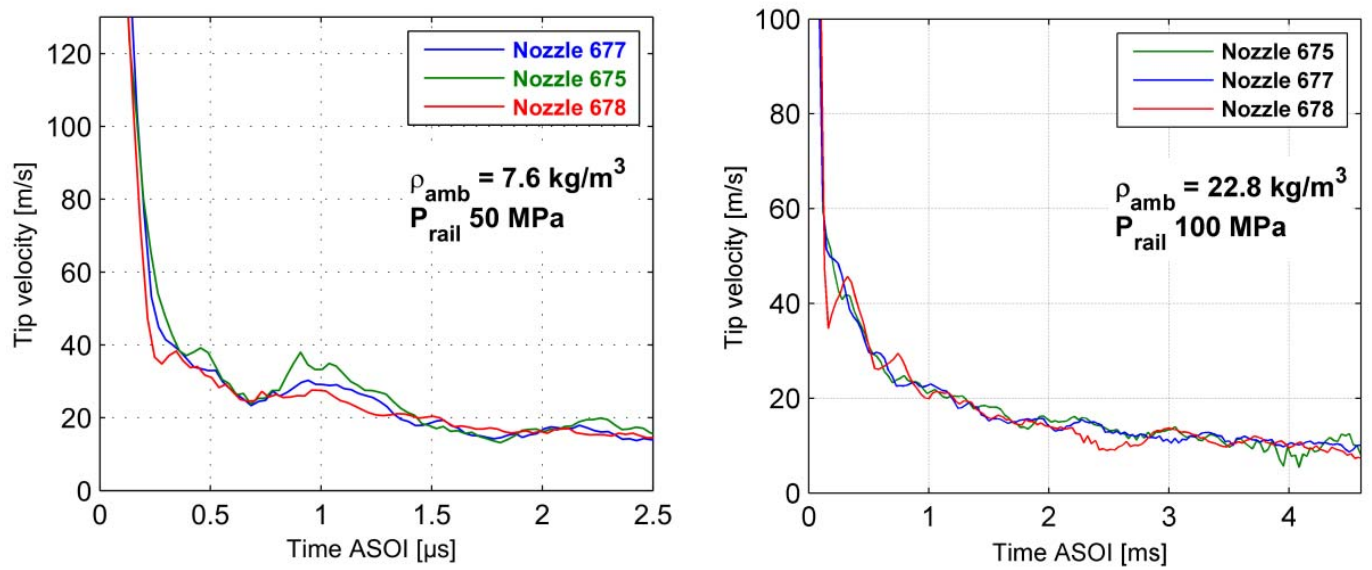

Figure 6

PUBLISHED AS: Experimental Thermal and Fluid Science 53 (2014) 236-243 http://dx.doi.org/10.1016/j.expthermflusci.2013.12.014 


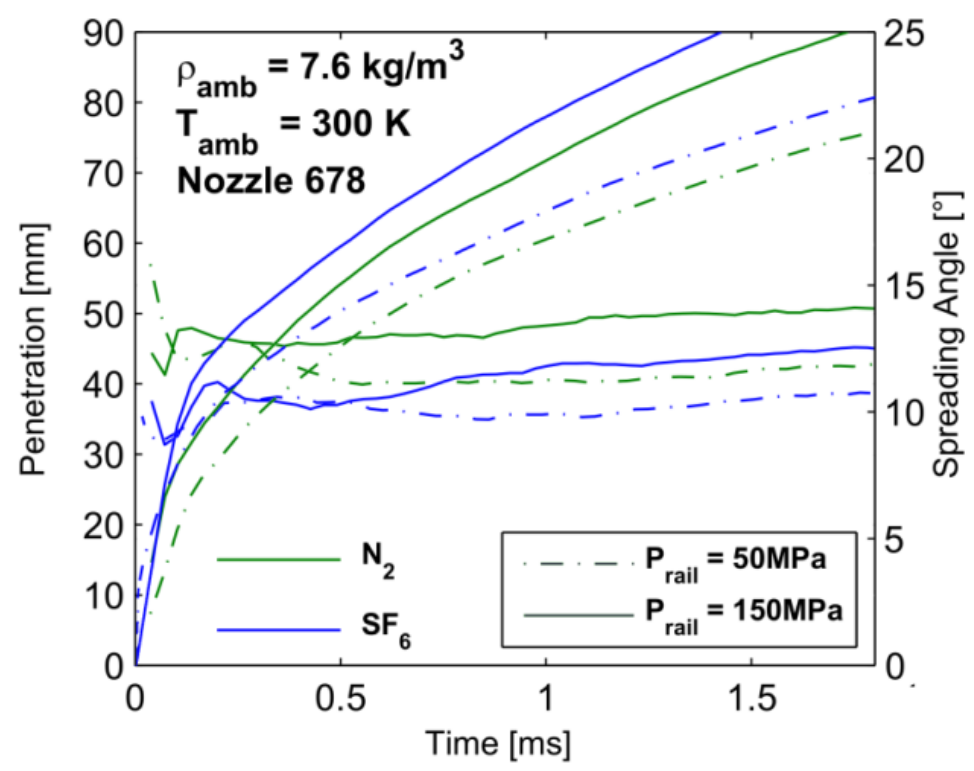

Figure7
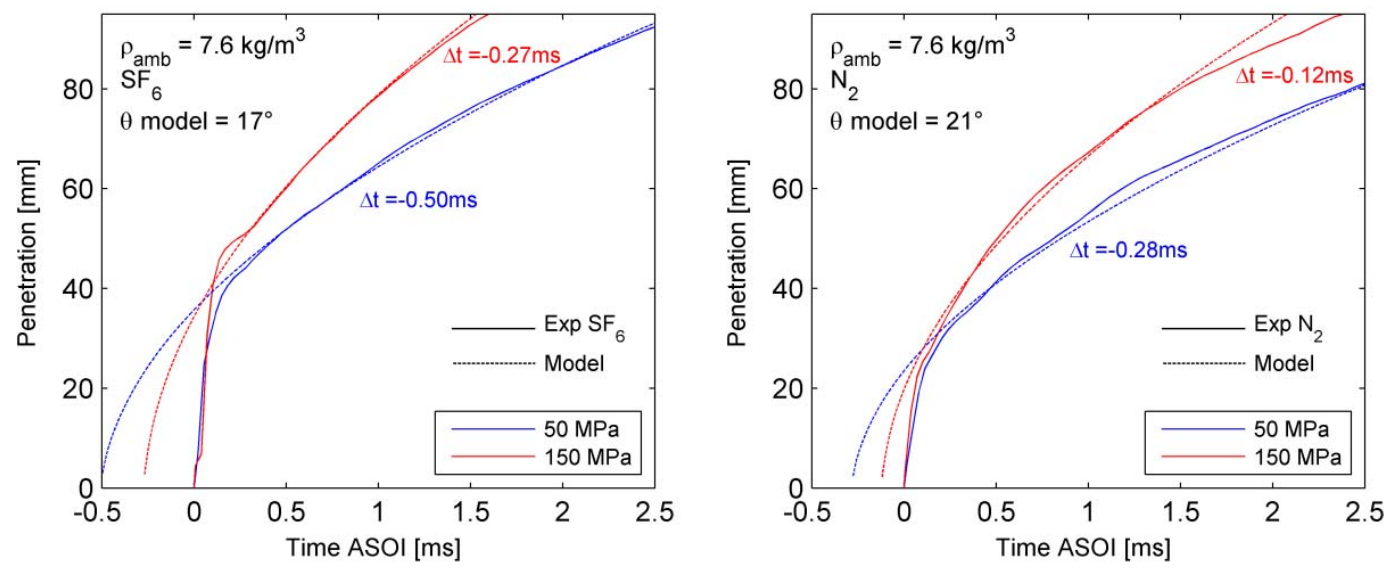

Figure 8

PUBLISHED AS: Experimental Thermal and Fluid Science 53 (2014) 236-243 http://dx.doi.org/10.1016/j.expthermflusci.2013.12.014 

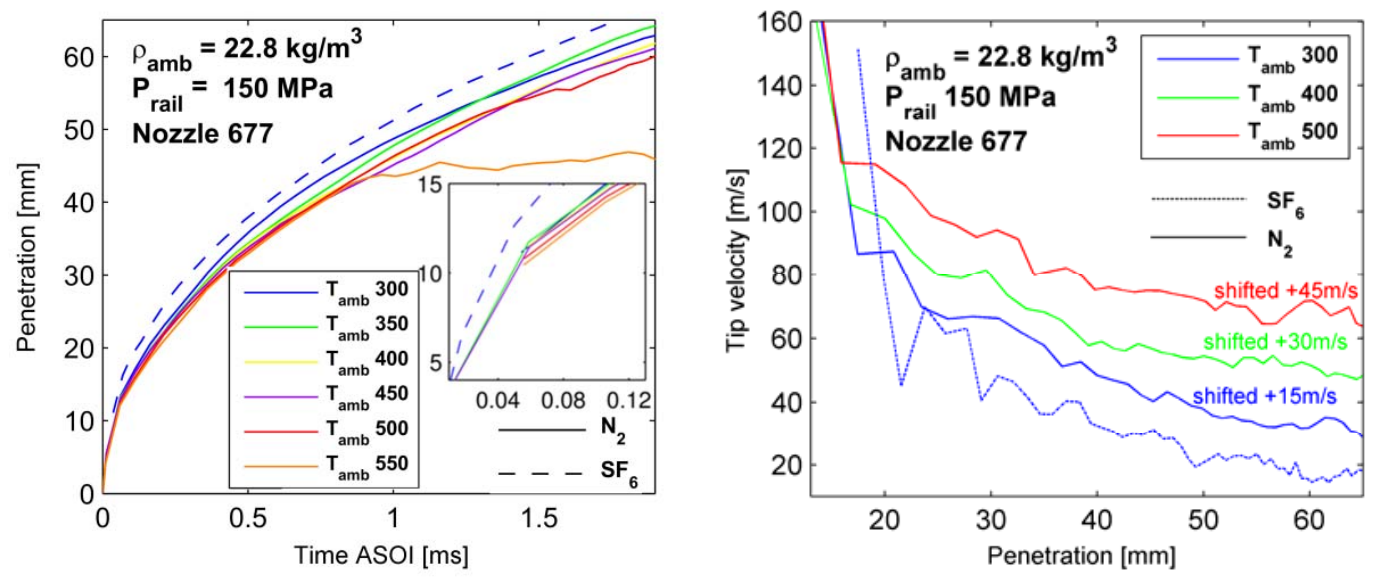

Figure9

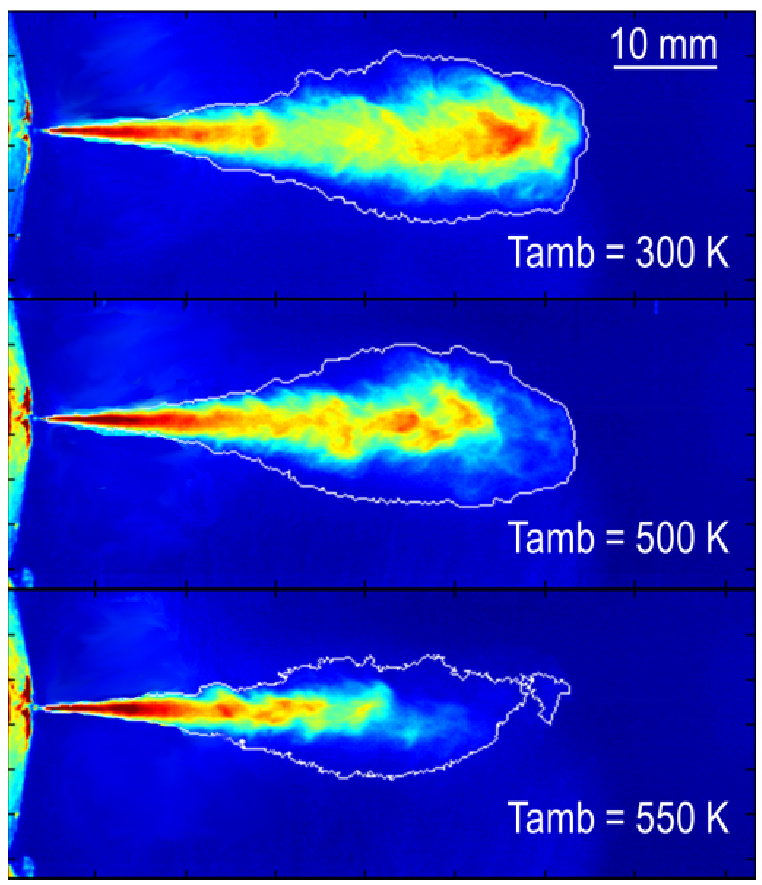

Figure10

PUBLISHED AS: Experimental Thermal and Fluid Science 53 (2014) 236-243 http://dx.doi.org/10.1016/j.expthermflusci.2013.12.014 


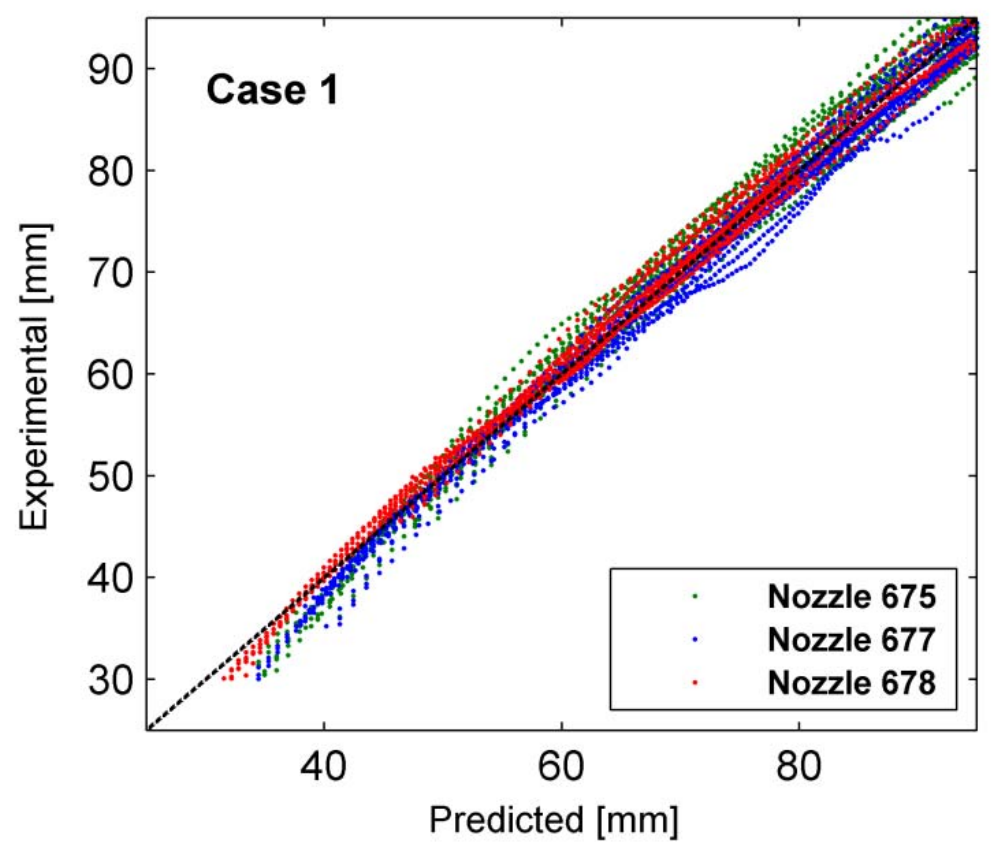

Figure11

PUBLISHED AS: Experimental Thermal and Fluid Science 53 (2014) 236-243 http://dx.doi.org/10.1016/j.expthermflusci.2013.12.014 